\title{
A novel device to measure gaseous permeability over a wide range of pressure: Characterisation of slip flow for Norway spruce, European beech and wood-based materials
}

\author{
Wei AI, Hervé DUVAL, Floran PIERRE and Patrick PERRÉ* \\ Laboratoire de Génie des Procédés et Matériaux, CentraleSupélec, Université Paris-Saclay, \\ Châtenay-Malabry, 92290, France \\ Corresponding author: patrick.perre@centralesupelec.fr
}

\begin{abstract}
A novel device was conceived and built to measure the apparent gaseous permeability of porous media over a large range of permeability values $\left(10^{-10}\right.$ to $\left.10^{-18} \mathrm{~m}^{2}\right)$ and mean pressures ( 1 bar to down to ca. 40 mbar). An extensive series of experimental data are presented and analysed for various porous media: (1) Norway spruce (Picea abies) and
\end{abstract} European beech (Fagus silvatica) in the three anatomical directions, and, for comparison, (2) three simpler porous media, i.e., an autoclaved aerated concrete (AAC, light concrete) and two wood-based panels. For all porous media, the intrinsic permeability, the gas slippage factor, and the effective pore size were determined from the variations of the apparent permeability as a function of mean pressure. These results are in good agreement with those of previous studies for spruce and bring new insights for beech and wood-based materials, in general. For all products, the effective pore sizes identified with the new instrument are closely linked to the medium morphology. In particular, it was found that, in spite of the huge anisotropic ratios between wood's longitudinal and tangential directions, the identified pore size is similar and corresponds to anatomical features: openings in margo for spruce and scalariform perforation plates for beech. Besides, the pore size identified for beech in the radial direction suggests that radial permeability is most probably controlled by the openings in ray cells, either pits or intercellular voids.

Keywords: Anisotropy, Klinkenberg factor, Knudsen number, Pore radius, Porous media. 


\section{Introduction}

Wood transformation processes or wood utilization are accompanied with mass transfer phenomena either by diffusion or by Darcy's flow. The understanding, prediction, and control of the processes, - such as drying, impregnation, bending, and the usage of barrels - require an extensive knowledge of wood properties.

Permeability is defined as the ease with which a fluid is transported through a porous material under the influence of a pressure gradient (Dullien 1992). The porosity (fraction of the volume of voids over the total volume), the tortuosity (the ratio of the length of a flow line between two points to the straight line distance between the points), the pore size, their distribution and their interconnectivity, and the flow regime - viscous (Darcy's law), slip, transition and Knudsen flow — are among the parameters that influence the apparent gaseous permeability. Except for the fluid properties, all of these factors are in relation to wood anatomy and other intrinsic wood properties. For example, in the longitudinal (1) direction, the material flow is primarily through the axially oriented elements, namely: tracheids interconnected by bordered pits in softwoods (Coté 1958), and vessels and partly fibres in hardwoods. The permeability varies roughly from $10^{-10}$ to $10^{-14} \mathrm{~m}^{2}$ (Choong and Kimbler 1971; Choong et al. 1974; Perré and Karimi 2002). These orders of magnitude are valid both for the apparent gaseous and liquid permeability. However, the former is always higher than the latter because the slip flow is negligible for liquid and because it is very difficult to avoid entrapped air in wood (Siau 1984). Typical permeability values in the transverse plane range from $10^{-15}$ to $10^{-18} m^{2}$ (Choong and Kimbler 1971; Perré 1987; Chen et al. 1998), even though extremely low values $\left(3.10^{-21} \mathrm{~m}^{2}\right)$ were reported for the Australian species spotted gum (Redman et al. 2012).

Wood tissues are organised to ensure an easy longitudinal sap migration: most cells have a large shape ratio with the length parallel to the tree axis, giving rise to impressive 
anisotropy ratios (Perre 2007). In the radial (r) direction, the flow is able to pass through the horizontally-aligned rays, which can substantially contribute to gaseous permeability (Balantinecz 1963; Comstock 1970; Matsumura et al. 1999; Usta and Hale 2006). The rpermeability is deeply influenced by the number and size of rays, which may vary greatly among different species. Consequently, the permeability is usually much smaller in the tangential $(\mathrm{t})$ direction than in the $\mathrm{r}$ direction. Based on a comprehensive literature review on various wood species, Comstock (1970) reported a range from 520 to 81,600 for the ratio of $1 / \mathrm{t}$ permeability and a range from 15 to 547,000 for the ratio of $1 / \mathrm{r}$ permeability. The corresponding ratios found in the present paper for Spruce heartwood are 25,000 and 2,300, respectively. In hardwood (HW), fluid flow is ensured by lines of vessel cells connected by perforation plates and in softwood (SW) by tracheids, namely earlywood (EW) tracheids, connected by bordered pits (Comstock 1967). For beech, ratios of 65,000 and 3,000 were determined by Perré (2007) concerning the $1 / \mathrm{t}$ and $1 / \mathrm{r}$ ratios, respectively. As a combination of wood variability and anisotropy ratios, wood gaseous permeability presents a wide range of values, typically 10 decades from $10^{-10}$ to $10^{-20} \mathrm{~m}^{2}$.

The pressure dependent flow regime is another factor that influences the gaseous permeability. When a rarefied gas is forced to flow through wood, a non-Darcian flow can occur, which influences the apparent permeability. Heid et al. (1950) claimed that gas permeability leading to values at low pressures, is the result of gas molecule slips near a solid wall. In general, the slippage effect becomes important when the mean free path of gas molecules is comparable to the smallest structural dimensions (vessel radius and pit aperture) along the flow pathway. The Knudsen number, $K_{n}$, which is well suited to classify flow regimes, is a dimensionless parameter defined as the ratio of the mean free path $\lambda$ and the pore radius $r$ : 


$$
K_{n}=\frac{\lambda}{r}
$$

The $\lambda$ can be approached by the kinetic gas theory. Under the hard sphere gas approximation (Hirschfelder et al. 1954) it is:

$$
\lambda=\frac{16 \mu_{g}}{5 P} \sqrt{\frac{R T}{2 \pi M}}
$$

According to Eq. (2), the mean free path at $25^{\circ} \mathrm{C}$ equals $69 \mathrm{~nm}$ at atmospheric pressure and $1.38 \mu \mathrm{m}$ at 50 mbar. With the order of magnitude of $0.2 \mu \mathrm{m}$ for the largest opening in the margo in the bordered pits of SW (Siau 1984), the Knudsen number ranges from ca. 0.35 to 7 over this range of pressure. These data emphasise the effect of slip flow that might be encountered in wood.

Whatever the sample, the apparent permeability always increases with the reciprocal pressure. This is due to the slippage of gas molecules at the wall of the pore that starts to be important when the Knudsen number becomes higher than 0.1. Klinkenberg (1941) proposed a linear equation between the apparent permeability $K_{a p p}$ and the reciprocal mean pressure $1 / \bar{P}:$

$$
K_{a p p}=K_{\infty}\left(1+\frac{b}{\bar{P}}\right)
$$

The intrinsic permeability $K_{\infty}$ corresponds to a flow without slip flow, which would be obtained at infinite pressure (a perfect zero velocity at the solid walls is ensured with a mean free path equal to zero). The Klinkenberg's factor $b$ can be related to the effective pore radius $\langle r\rangle$ via the Knudsen number $K_{n}$ :

$$
\frac{b}{\bar{P}}=4 c K_{n}=\frac{4 c \lambda}{\langle r\rangle}
$$


where $c$ is a constant value close to the unit (Klinkenberg 1941). With Eq. (2), the effective pore radius is related to factor $b$ by the following equation:

$$
\langle r\rangle=\frac{64 c \mu}{5 b} \sqrt{\frac{R T}{2 \pi M}}
$$

Thus, the analysis of the variations (due to slippage) of $K_{\text {app }}$ as a function of $1 / \bar{P}$ provides not only the intrinsic (or Darcy) permeability (intercept at $1 / \bar{P}=0$ ), but it is also an estimate of the effective pore radius (through Eqs. 3 to 5).

The studies on slip flow in wood are rare and often restricted to the longitudinal direction because (1) the slippage analysis requires permeability measurement over a large range of mean pressure for each sample in each direction, and (2) measurements are difficult as a function of mean pressure, due to the very low transverse permeability of wood.

Among the few available works in this field, Comstock (1967) compared the 1permeability with liquids and different gases, where the slip flow effect is obvious. At the same pressure level, the apparent permeability depends on the nature of the gas, but the intercept corresponding to an infinite pressure, the intrinsic permeability does not. Some other works were also devoted to the slip flow in 1-direction (Bolton and Petty 1978: Petty and Purich 1980; Lu and Avramidis 1999). We found only two papers concerning slip flow data in both 1- and t- directions (Petty and Preston 1969; Petty 1970). The quoted authors successfully identified the effective pore radius involved in the fluid pathway for SW species by means of the slippage factor and found similar data for both in 1- and t-directions corresponding to the typical opening in the margo of bordered pits.

The literature review (Table 1) shows the lack of data on slip flow measurements, especially in t-direction. Most of these measurements were done decades ago with rigorous but tedious methods. Most of the published works determine the flow rate by the change of water level in a tube over a certain time period. The aim of this paper is (1) to determine the 
gaseous permeability under the influence of slip flow, and (2) to identify the effective pores sizes from the analysis of the apparent permeability variations as a function of mean pressure. A novel in-house experimental apparatus was designed to measure the apparent gaseous permeability over a wide range of permeability values $\left(10^{-10}\right.$ to $\left.10^{-18} \mathrm{~m}^{2}\right)$ and a large range of mean gaseous pressures ( 1 bar down to ca. $30-40$ mbar ). Thanks to accurate pressure sensors and appropriate data analysis, gas flowrates in the set-up can be determined without additional instrumentation. In this way, any flowmeter deviations can be avoided under rarefied gas conditions. The usually cumbersome scan in mean pressure for one sample can be avoided by means of high performance vacuum valves in automatic actuators while keeping maximum accuracy.

In the following section Materials and methods only the isothermal model of the new device will be reported; the full non-isothermal model is presented in the appendix. Depending on the permeability value, either the isothermal or the non-isothermal approach will be applied to (1) Norway spruce (Picea abies) and European beech (Fagus silvatica) in different material directions, and (2) to three simpler porous media, such as an autoclaved aerated concrete (AAC, light concrete) and two wood-based panels. Then the analysis of the apparent permeability variations will be presented as a function of mean pressure. In focus is the effective pore size, which will be related to structural and anatomical features.

\section{Nomenclature, materials and methods}

$\begin{array}{lll}A_{\text {sample }} & \text { Surface area of sample } & \mathrm{m}^{2} \\ b & \text { Klinkenberg's slip factor } & \mathrm{Pa} \\ c & \text { Constant in equation (4) } & (-) \\ c_{p} & \text { Specific heat capacity } & \mathrm{J} \cdot \mathrm{kg}^{-1} \cdot \mathrm{K}^{-1} \\ C_{v} & \text { Heat capacity at constant volume } & \mathrm{J} \cdot \mathrm{K}^{-1} \\ \mathrm{EW} & \text { earlywood } & \\ h & \text { Heat transfer coefficient } & \mathrm{W} \cdot \mathrm{m}^{-2} \cdot \mathrm{K}^{-1} \\ k & \text { Kozeny constant } & \end{array}$




\begin{tabular}{|c|c|c|}
\hline$K$ & Permeability & $m^{2}$ \\
\hline$K_{a p p}$ & Apparent permeability & $m^{2}$ \\
\hline$K_{\infty}$ & Intrinsic permeability & $m^{2}$ \\
\hline$K_{n}$ & Knudsen number & $(-)$ \\
\hline$\ell$ & Sample thickness & $m$ \\
\hline LW & latewood & \\
\hline$M$ & Molar mass & kg.mol ${ }^{-1}$ \\
\hline$n$ & Number of moles & mol \\
\hline$P$ & Pressure & $P a$ \\
\hline $\bar{P}$ & Average pressure & $P a$ \\
\hline$Q$ & Volume flow & $m^{3} \cdot s^{-1}$ \\
\hline$Q_{m}$ & Mass flow & $k g . s^{-1}$ \\
\hline$r$ & Pore radius & $m$ \\
\hline$\langle r\rangle$ & Effective pore radius (equation 4) & $m$ \\
\hline$r_{h}$ & Hydraulic radius (equation 12) & $m$ \\
\hline$R$ & Gas constant & $8.31446 J^{J} . \mathrm{mol}^{-1} \cdot K^{-1}$ \\
\hline$S$ & Entropy & $J . K^{-1}$ \\
\hline$t$ & Time & $s$ \\
\hline$T$ & Temperature & $K$ \\
\hline$v_{g}$ & Apparent velocity of gas & $m . s^{-1}$ \\
\hline$V$ & Tank volume & $m^{3}$ \\
\hline$x$ & Coordinate across the sample thickness & $m$ \\
\hline \multicolumn{3}{|c|}{ Greek letters } \\
\hline$\alpha$ & Factor in equation (15) & Pa. $m^{2 \beta}$ \\
\hline$\beta$ & Exponent in equation (15) & $(-)$ \\
\hline$\gamma$ & Ratio of specific heats & $(-)$ \\
\hline$\varepsilon$ & Porosity & $(-)$ \\
\hline$\mu_{g}$ & Dynamic viscosity of gas & Pa.s \\
\hline$\rho_{g}$ & Density of gas & $k g \cdot m^{-3}$ \\
\hline$\tau$ & Time constant of pressure relaxation & $s$ \\
\hline$\phi$ & Sample support diameter & $m$ \\
\hline \multicolumn{3}{|c|}{ Subscripts } \\
\hline int & Internal & \\
\hline ext & External & \\
\hline$g$ & $\mathrm{Gaz}$ & \\
\hline $\operatorname{tank}$ & Tank & \\
\hline wall & Tank wall & \\
\hline 1 & Relative to tank 1 & \\
\hline 2 & Relative to tank 2 & \\
\hline
\end{tabular}


Sampling: Specimens of Norway spruce (Picea abies, from the Risoux Forest in the East of France) and beech (Fagus sylvatica, from the Rambouillet Forest in the Paris region), low density fiberboard (LDF), medium density fiberboard (MDF), and an autoclaved aerated concrete (AAC, as reference for porous materials) are in focus. Wood specimens were dried under natural conditions. Data of average basic density (BD, oven-dry mass to green volume): $360 \mathrm{~kg} \cdot \mathrm{m}^{-3}$ for Norway spruce and $560 \mathrm{~kg} \cdot \mathrm{m}^{-3}$ for European beech. The MDF, LDF, and AAC have densities of $737 \mathrm{~kg} \cdot \mathrm{m}^{-3}, 156 \mathrm{~kg} \cdot \mathrm{m}^{-3}$, and $559 \mathrm{~kg} \cdot \mathrm{m}^{-3}$, respectively.

Defect-free samples were cut from the heartwood zone of the wood logs (Figure 1). Due to the high values of permeability for wood in 1-direction, samples with a cylindrical shape with a diameter of $18 \mathrm{~mm}$ and thickness of $30 \mathrm{~mm}$ were cut with a hole saw. Because of the low permeability in the t-direction, discs with a diameter of $72 \mathrm{~mm}$ and a thickness of $10 \mathrm{~mm}$ were prepared. For t-sample, the radius of heartwood was not enough to have the same geometry. Therefore. samples with a diameter $(\varnothing)$ of $18 \mathrm{~mm}$ and a thickness of $8 \mathrm{~mm}$ were prepared (Figure 1). Other cylindrically shaped sample dimensions: AAC (18 $\mathrm{mm} \varnothing \times$ $25 \mathrm{~mm}$ thickness), LDF $18 \mathrm{~mm} \varnothing \times 30 \mathrm{~mm}$ thickness, and MDF (18 $\mathrm{mm} \varnothing \times 15 \mathrm{~mm}$ thickness). To avoid lateral leakage during permeability measurements, a surface prone to impervious contact with the rubber tube is required. This is obtained by coating the lateral surfaces of the sample with two successive layers of epoxy resin. In the case of LDF, because of its high porosity, a layer of epoxy resin was applied on a band of aluminium foil, which was itself rolled against the lateral face of the sample, before the resin had hardened. Then a layer of epoxy resin was coated on the external surface of the film to produce a surface sufficiently smooth to ensure air tightness.

Experimental apparatus: An in-house device was conceived to measure permeability over a large range of values and average pressure. The device comprises two rigid tanks 
(stainless steel or duralumin) of identical volume built in series with a sample support, a system of vacuum valves with actuators, and two accurate pressure gauges (Figure 2). The system is completely airtight and isolated from its environment: the pressure in the system can just be set with the aid of two valves connected either to compressed gas or vacuum. The entire system is placed in a temperature-controlled chamber, built on demand (accuracy $\pm 0.5^{\circ} \mathrm{C}$, StD $0.04^{\circ} \mathrm{C}$ ). This system allows a pressure gap to be imposed on the sample and the resulting gas flux to be determined by the evolution of pressures $P_{1}$ and $P_{2}$ in volumes $V_{1}$ and $V_{2}$ respectively. As the system is completely isolated from the atmospheric pressure, any measurement gas can be chosen in the compressed gas cylinder. In the present work, all measurements were carried out with air.

Particular attention was paid to the design of the confinement cell to ease the handling of samples and to ensure air tightness during experiments. It is inspired by the ALU-CHA system developed by Perré and Agoua (2002). The support consists of an aluminium pipe covered inside by a piece of rubber tube having a smaller diameter than the aluminium cylinder (Figure 2). The air between the pipe and the rubber tube can be aspirated using a vacuum pump. This causes the adhesion of the rubber tube to the pipe, allowing the implementation of the sample inside the support. Vacuum grease on the lateral face of the sample ensures air tightness around the sample and the system is combined with an overpressure of more than 2 bar applied inside the rubber tube during measurement. The experimental protocol comprises several steps: 1) Valves 3, 4, and 5 are open to ensure a quasi-even pressure in the entire system. 2) The desired measurement pressure is obtained either by increasing or decreasing the pressure, respectively by opening valves $V_{1}$ or $V_{2}$. The flux is limited due to the needle valve placed in series with $\mathrm{V}_{1}$ and $\mathrm{V}_{2}$, which allows the pressure to vary gently when a valve is open. 3$)$ The bypass valve $\left(V_{5}\right)$ is closed, which allows a short action of valve $V_{1}$ or $V_{2}$ to establish a pressure gap between tanks $T_{1}$ and $T_{2}$. 4) All 
valves are maintained in a closed position until isothermal conditions. This regime is assessed with type-K thermocouples placed in the tanks. 5) The solenoid valves $V_{3}$ and $V_{4}$ are opened, and the evolution of $\mathrm{P}_{1}$ and $\mathrm{P}_{2}$ (relaxation of the pressure gap) are recorded with highly sensitive pressure sensors (GE Druck, TERPS RPS/DPS 8000) able to measure pressure in the range 0 to 2,000 mbar with a precision of $0.01 \%$.

Steps 1 to 5 are repeated for several values of the average gaseous pressure in the sample. Step 4 can be bypassed for samples with low permeability, as the measurement time is much longer than the transient thermal regime in such cases.

Two sets of tanks (0.2 and 24 litres) and two sample supports (Support $\mathrm{S}_{1}$ : interior $\varnothing$ $78 \mathrm{~mm}$, exterior $\varnothing 88 \mathrm{~mm}$, and sample length up to $20 \mathrm{~mm}$, and support $\mathrm{S}_{2}$ : interior $\varnothing$ $18 \mathrm{~mm}$, exterior $\varnothing 28 \mathrm{~mm}$, and length up to $30 \mathrm{~mm}$ ) permits the measurement over a wide range of pressure ( 20 mbar to 2 bar ) and permeability $\left(10^{-10}\right.$ to $10^{-18} \mathrm{~m}^{2}$ ).

Depending of the sample and the measurement parameters (tank volume, sample geometry, and average pressure), the relaxation time ranges from a period of seconds to several hours. However, the curve shapes always depict a clear and orderly symmetrical evolution towards the average pressure. For samples with low permeability at low pressure, such a behaviour requires the system to be perfectly isolated from the atmospheric pressure: all connections are based on the high vacuum technology, and the connections to the tanks or the sample support are either soldered or sealed with a sealing resin (Loctite 586).

Figure 3 depicts some examples of experimental data obtained for contrasted samples. With a carefully selected parameter set, a wide range of values can be measured. For each test, the time constant of pressure relaxation $\tau$ is defined as follows:

$$
\tau=\left.\frac{P_{2}-P_{1}}{d P_{1} / d t}\right|_{t=0^{+}}
$$


This time constant governs the thermal regime of the experimental device. This constant increases significantly when the mean pressure decreases. This is beneficial for highly permeable samples, but the determination of the apparent permeability at low mean pressure is even more difficult for samples with very low permeability.

Analysis of raw data: The apparent permeability $K_{a p p}$ is based on Darcy's law:

$$
v_{g}=-\frac{K_{a p p}}{\mu_{g}} \nabla P
$$

A rigorous expression of the volume flow $Q$ can be obtained for any pressure gap imposed on the sample by integrating Eq. (7) along a sample of thickness $\ell$, with the gas density expressed in the ideal gas law, and assuming a constant temperature $T$ :

$$
Q_{m}=A_{\text {sample }} \frac{K_{a p p}}{\mu_{g}} \frac{M}{R T} \frac{\left(P_{1}^{2}-P_{2}^{2}\right)}{2 \ell}
$$

Obviously, this expression ensures a uniform mass flow $Q_{m}$ through the sample. Introducing the gas average pressure, $\bar{P}=\left(P_{1}+P_{2}\right) / 2$, the experimental mass flow through the sample is given by:

$Q_{m}=\frac{K_{a p p} A_{\text {sample }}}{\mu_{g}} \frac{\bar{P} M}{R T} \frac{\left(P_{1}-P_{2}\right)}{\ell}$

To deduce the permeability from Darcy's law, the key issue is then to obtain the flux through the sample via the pressure parameters. For most wood species, the permeability is quite low in the transverse plane, radial or tangential directions, with typical values in the range $10^{-15}$ to $10^{-18} \mathrm{~m}^{2}$. Under such conditions, the experiment duration is in the order of $1 \mathrm{~h}$ and the experimental system is in isothermal conditions. With the assumption of constant temperature, this mass flow depends only on the pressure variations:

$Q_{m}=-V_{1} \frac{M}{R T} \frac{d P_{1}}{d t}=V_{2} \frac{M}{R T} \frac{d P_{2}}{d t}$ 
Finally, a combination of equations (9) and (10), in the case of identical volumes $\left(V=V_{1}=V_{2}\right)$, gives the expression to be used for determination of the apparent permeability from the experimental data under the isothermal regime:

$$
K_{\text {app }}=\frac{\mu_{g} V \ell}{A_{\text {sample }}} \frac{1}{2 \bar{P}} \frac{d\left(\ln \left(P_{1}-P_{2}\right)\right)}{d t}
$$

In case of two tanks of equal volume, the average pressure $\bar{P}$ is constant throughout the entire experiment. Therefore, Eq. (11) indicates that the time derivative of $\ln \left(P_{1}-P_{2}\right)$ should be constant. The apparent permeability is then simply deduced from the slope of the function $f(t)=\ln \left(P_{1}(t)-P_{2}(t)\right)$ obtained by a linear regression.

Figure 4 depicts one typical example of experimental measurement (Norway spruce in tdirection). Several conclusions can be drawn from this example: 1) Due to the choice of identical volumes, the average pressure remains constant during the measurements: $\bar{P}=298.6 \pm 0.9 \mathrm{mbar}$. This remains valid as long as the initial pressure gap is much smaller than the mean pressure; 2) Equation (11) holds, as $\ln \left(P_{1}-P_{2}\right)$ plotted against time is perfectly linear; 3) In spite of the very small pressure gap at the end of this experiment (6.14 mbar ), the curve only minimally becomes noisy (see the inset graph), which confirms the excellent quality of our pressure sensors.

In case of highly permeable samples, the simple assumption of isothermal regime fails. This is why a full computational model was derived to analyse experimental data in any real regime. The detail of this model and its computational solution are detailed in appendix. This model is able to quantify the error, when assuming ideal conditions (Table 2) and permits the best strategy for data analysis to be derived: 1) For samples of low permeability, an isothermal regime is assumed and $K_{a p p}$ is simply computed by Eq. (11). 2) For highly permeable samples, the full model is used to analyse experimental data. As this model 
requires the permeability value to compute the pressure evolutions, an inverse procedure was adopted. The objective function is the mean squared difference between the simulated and measured pressure evolutions $\left(P_{1}\right.$ and $\left.P_{2}\right)$.

\section{Results and discussion}

For each sample, a series of measurements were performed at different mean pressures and represent the apparent permeability as a function of reciprocal mean pressure. The entire set of experimental data collected under isothermal regimes is depicted in Figure 5. Note that the measurement of spruce in r-direction has not been achieved, just because its permeability is beyond the range of our device $\left(10^{-18} \mathrm{~m}^{2}\right)$. Figure 6 completes the set of data for samples too permeable to obtain an isothermal regime. In these cases, the apparent permeability was determined by an inverse procedure (see appendix). One has to keep in mind that each single point of all of these graphs required one gas relaxation experiment to be performed.

The intrinsic permeability $K_{\infty}$ is simply obtained by the intercept of the fitted straight line at the origin, whereas the slope of this line gives the value of the Klinkenberg's factor $b$ (Eq. 4). Table 3 summarises all data determined from our dataset: intrinsic permeability, factor $b$, and effective pore radius. The latter was determined by Eq. (5) with $c=1$.

For spruce in 1-direction, the intrinsic permeability is found to be $2.410^{-14} \mathrm{~m}^{2}$ which is close to the permeability of red spruce determined by Rice $1996\left(1.710^{-14} \mathrm{~m}^{2}\right)$. For the beech in the 1-direction, the intrinsic permeability is found to be $5.910^{-12} \mathrm{~m}^{2}$ which is in close agreement with measurements of Perré (2002), who found an average permeability in heartwood of beech of $5.1410^{-12} \mathrm{~m}^{2}$. The intrinsic permeability values found here for spruce and beech agree also with previous measurements performed by one of the authors based on a different experimental device (Tarmian and Perré 2009). 
However, the real novelty lies in the effect of mean pressure for different directions of the same species. In case of spruce heartwood, the value of factor $b$ found in t- and 1orientations is almost the same, in spite of a 4-decade difference concerning the anisotropy ratio! Once converted into an effective pore radius, the value for spruce is $0.24 \mu \mathrm{m}$ in the tdirection and $0.54 \mu \mathrm{m}$ in the 1-direction. These values have to be compared with the largest of the small openings in the margo of bordered pits. Due to the propensity of bordered pits to be aspirated in earlywood, it is likely that the active part of dried spruce regarding fluid flow is in the latewood (Panshin and de Zeeuw 1980; Domec and Gartner 2002; Almeida et al. 2008). These anatomical factors result in a reduced permeability in heartwood, usually with reduced apparent pit-pore sizes (Wang et al. 1996). Therefore, it is remarkable that these orders of magnitude of pore size correspond to the pore opening between the margo microfibrils in latewood pits (Domec et al. 2006). This confirms that, whatever the flow direction, the resistance to the flow takes place in the same anatomical elements. These orders of magnitude of the pore size are also in good agreement with those determined indirectly from permeability and mass diffusivity values using a simple pore morphology (Agoua and Perré, 2010). The slightly higher pore radius found in the 1-direction can be explained by the probability of connection of the largest pores: the pathway in the t-direction enforces the gas flow through a much higher number of pits, resulting in a much smaller probability to have a continuous pathway with large pores. In this sense, our results seem more consistent with those of Petty (1970), who found for Sitka spruce a larger effective radius in t-direction (ca. $0.6 \mu \mathrm{m}$ ) than in 1-direction (ca. $0.14 \mu \mathrm{m}$ ).

In case of beech heartwood, the axial experiment depicts a pore radius of ca. $7 \mu \mathrm{m}$, which is also the typical size of scalariform openings that prevail between vessel elements in latewood. As simple perforations prevail in earlywood, this typical pore radius could also be the largest pore in intravascular pits, as these aligned pits can be elongated and even become 
scalariform (Jacquiot et al. 1973). Clearly, in this diffuse-porous hardwood, the gas flow occurs mainly in the vessels. Inside these vessels, the resistance to the flow along the pathway is high because of the scalariform perforations plates or intervascular pits, as the vessels themselves have a diameter ranging from 50 to $75 \mu \mathrm{m}$ (Jacquiot et al. 1973; Perré and Karimi 2002). The same order of magnitude is found in the t-direction, which is a completely new result, which suggests that the same openings serve for the t-flow. This confirms the importance of intervascular pits, as such openings are required for the flow along the tdirection from one vessel line to the other. The t-pathway could then consist of vessel lines interconnected to allow for a t-progression at the cost of a huge tortuosity. The small number of possible pathways and the numerous intervascular pits required to progress along the $t-$ pathway could explain the large anisotropy ratio (longitudinal over tangential). The openings found in beech in the r-direction are smaller ( 0.3 to $1.7 \mu \mathrm{m})$, which suggests that the fluid pathway involves different openings, probably the openings in the large rays existing in beech or, most probably, the inter-cellular voids between ray cells (Wheeler et al. 1989).

Finally, the pore radius in fibreboard is also consistent with the structure of these panels: roughly $12 \mu m$ in LDF and $7 \mu m$ in MDF. The size of the pore radius between neighbouring fibres is in the order of the fibre diameter for a low density panel, but decreases due to the compression rate required to obtain the higher density of MDF.

Light concrete is known to have a structure of large pores (up to some millimetres) connected by much smaller openings, which is, again, consistent with the micrometric pore size found by means of the slip flow as an indirect pore gauge. These results, including the intrinsic permeability values, are in good agreement with published works (Wägner et al. 1995).

The unique data set proposed in the present work deserves further analysis. Using semiempirical relations originally established for simple porous media such as packed beds of 
particles, the factor $b$ can be expressed as a function of the intrinsic permeability. According to the Carman-Kozeny equation (Carman 1937), Darcy's permeability can be expressed as a function of structural parameters:

$K_{\infty}=\frac{\varepsilon r_{h}^{2}}{k}(12)$

where $\varepsilon$ is the porosity of the sample, $r_{h}$ is the hydraulic radius of the porous medium (defined as the free volume to wetted area ratio), and $k$ is the so-called Kozeny constant. The analysis of a large volume of data on packed beds indicates that $k \simeq 5$, independent of particle's shape and bed's porosity from $\varepsilon=0.26$ to $\varepsilon=0.8$ (Happel and Brenner 1991). Then, from expressions (5) and (12), assuming that $r_{h} \cong\langle r\rangle$, Eq. 13 can be obtained:

$b \cong\left(\frac{64}{5} c \mu \sqrt{\frac{R T}{2 \pi M}}\right) \sqrt{\frac{\varepsilon}{k}} K_{\infty}^{-1 / 2}$

For air at $25^{\circ} \mathrm{C}$, assuming $c=1, k=5$, and $\varepsilon=0.8$, the factor $b$ is given approximately by:

$b \cong 1.110^{-2} K_{\infty}^{-1 / 2}(14)$

From Eq. (14) follows that factor $b$ is larger for samples with lower permeability values. This trend is confirmed by experimental data. Several authors proposed similar relations as described in Eq. (14), but with adjusted coefficient and exponent to fit some experimental data:

$b=\alpha K_{\infty}^{-\beta}$

It appears that the values of constants $\alpha$ and $\beta$ depend on the dataset in a quite moderate way (respectively 0.777 and 0.39 in Heid et al. 1950, 0.86 and 0.33 in Jones and Owens 1979, and 0.251 and 0.36 in $\mathrm{Wu}$ et al. 1998). The fitted power factor $\beta$ is ca. 0.35 , slightly lower than the value 0.5 calculated by Eq. (13). 
Eqs. 14 and 15 suggest that the data can be presented in one plot. Hence, Figure 7 presents the values of the slippage factor as a function of the intrinsic permeability for the materials investigated in the present work. The values of the intrinsic permeability are spread over 8 decades, from $10^{-10}$ to $10^{-18} \mathrm{~m}^{2}$. This allows a useful comparison with the general expressions for factor $b$, based on the semi-empirical (14) or empirical relation (15). These expressions give similar values for highly permeable media, but they predict a quite different trend for very low values of permeability. The overall trend found here is in quite accurate agreement with the empirical Eq. (15). In particular, it is noticeable to observe that all the samples in focus from isotropic products (light concrete, LDF, and MFD) are almost exactly on this curve, in spite of the large permeability range, from $10^{-10}$ to $10^{-15} \mathrm{~m}^{2}$.

\section{Conclusion}

A novel experimental device was designed to measure the apparent gaseous permeability over a wide range of mean pressure. Thanks to an inverse analysis based on a computational model, this device does not need any flow meter and is able to permeability determination over large ranges of mean pressure and permeability ( $30 \mathrm{mbar}$ to $1 \mathrm{bar}$ and $10^{-10}$ to $10^{-18} \mathrm{~m}^{2}$ ).

Experimental data were analysed for various porous media: Norway spruce and European beech in three anatomical directions, two wood-based panels, and one reference porous medium (autoclaved aerated concrete. AAC). The presented large dataset including different anatomical directions over a large range of mean pressure is consistent and unique, and the permeability values presented are in good agreement with published data. The slippage factors obtained for fibreboards are consistent with their structure, with an effective pore radius in the order of fibre radii, which are reduced at higher panel density. New findings arose also for directional behaviour in wood: (1) In spite of the huge anisotropic ratios found between the 
longitudinal and tangential directions, the effective pore size is the same and corresponds to anatomical features (openings in margo for spruce and scalariform perforation plates for beech). (2) The pore size found for beech in the radial direction suggests that other openings are involved, certainly including openings in ray cells (pits or intercellular voids). 


\section{References}

Agoua, E., Perré, P. (2010) Mass transfer in wood: Identification of structural parameters from diffusivity and permeability measurements. J. Porous Media 13:1017-1024.

Almeida, G., Leclerc, S., Perré, P. (2008) NMR imaging of fluid pathways during drainage of softwood in a pressure membrane chamber. J. Multiphase Flow 34:312-321.

Balantinecz, J.J. (1963) The influence of morphological factors upon liquid flow in Douglasfir wood under pressure. M.S. thesis, Univ. of Wash.

Bolton, A.J., Petty, J.A. (1978) The relationship between the axial permeability of wood to dry air and to nonpolar solvent. Wood Sci. Technol. 12:111-126.

Cai, L., Oliveira, L.C. (2007) Gas Permeability of Wetwood and Normal Wood of Subalpine Fir in Relation to Drying. Drying Techn., 25(3): 501-505.

Carman, P.C. (1937) Fluid flow through granular beds. Trans. Inst. Chem. Eng. 15:150-166.

Chen, P.Y.S., Zhang, G., Van Sambeek, J.W. (1998) Relationship among growth rate, vesel lumen area, and wood permeability for three hardwood species. Forest Prod. J. 48(3):87-90.

Choong, E.T., Kimbler, O.K. (1971) A technique of measuring water flow in woods of low permeability. Wood Sci. 4(1):32-36.

Choong, E.T., Tesoro, F.O., Manwiller, F.G. (1974) Permeability of twenty-two small diameter hardwoods growing on southern pine sites. Woods Fiber 6(1):91-101.

Comstock, G.L. (1967) Longitudinal permeability of wood to gases and nonswelling liquids. Forest Prod. J. 17:41-46.

Comstock, G.L. (1970) Directional permeability of softwoods. Wood Fiber Sci. 1(4):283-289.

Coté, W.A. (1958) Electron microscope studies of pit membrane structure; implications in seasoning and preservation of wood. For. Prod. J. 8:296-301.

Domec, J.C., Gartner, B.L. (2002) How do water transport and water storage differ in coniferous earlywood and latewood. J. Exp. Botany 53:2369-2379.

Domec, J.C., Lachenbruch, B., Meinzer, F.C. (2006) Bordered pit structure and function determine spatial patterns of air-seeding thresholds in xylem of douglas-fir (Pseudotsuga menziesii; Pinaceae) trees. American J. Botany 93(11):1588-1600.

Dullien, F.A.L. (1992) Porous Media: Fluid Transport and Pore Structure. Academic Press Inc., New York.

Happel, J., Brenner, H. (1991) Low Reynolds Number Hydrodynamics. Kluwer Academic Publishers, Dordrecht.

Heid, J.G., McMahon, J.J., Nielsen, R.F., Yuster, S.T. (1950) Study of the permeability of rocks to homogenous fluids. In : Drilling \& Production Practice. American Petroleum Institute, New York, 230-246.

Hirschfelder, J.O., Curtiss, C.F., Bird, R.B. (1954) Molecular theory of gases and liquids, John Wiley and Sons Inc., New York.

Jacquiot C., Trénard Y., Dirol D. (1973) Atlas d'anatomie des bois des angiospermes (essences feuillues). 2 volumes, CTB, Paris.

Jones F.O., Owens W.W. (1980) A laboratory study of low-permeability gas sands. J. Petroleum Techn. 1631-1640.

Klinkenberg, L.J. (1941) The permeability of Porous Media to Liquid and Gases. In : Drilling \& Production Practice. American Petroleum Institute, New York, 200-213.

Lihra, T., Cloutier, A., Zhang, S.Y. (2000) Longitudinal and transverse permeability of balsam fir wetwood and normal heartwood. Wood Fiber Sci. 32(2): 164-178.

Lu, J., Avramidis, S. (1999) Non-Darcian air flow in wood. Part 3. Molecular slip flow. Holzforschung 53:85-92. 
Matsumura, J., Booker, R.E., Ridoutt, B.G., Donaldson, L.A., Mikajiri, N., Matsunaga, H., Oda, K. (1999) Impregnation of radiata pine wood by vacuum treatment II: effect of pre-steaming on wood structure and resin content. J. Wood Sci. 45(6):456-462.

Panshin, A.J., de Zeeuw, C. (1980) Textbook of wood technology. Structure, Identification, Properties and Uses of the Commercial Woods of the United States and Canada. McGraw-Hill, New York.

Perré, P. (1987) Measurements of softwoods permeability to air: importance upon the drying model. Int. Commun. Heat Mass Transfer 14:519-529.

Perré, P., Agoua, E. (2002) Mass transfer in MDF (medium density fiberboards): identification of structural parameters from permeability and diffusivity measurements. $13^{\text {th }}$ International Drying Symposium, Drying'2002, Vol. A 178-187, Beijing, China Drying.

Perré, P. (2007) Fundamentals of wood drying. COST E15 and ARBOLOR, Nancy.

Perré, P., Karimi, A. (2002) Fluid migration in two species of beech (Fagus silvatica and Fagus orientalis): a percolation model able to account for macroscopic measurements and anatomical observations. Maderas Ciencia Tecnologia 4:50-68.

Petty, J.A., Preston, R.D. (1969) The dimensions and number of pit membrane pores in conifer wood. In: Proc. Roy. Soc. Lond. B172: 137-151.

Petty, J.A. (1970) Permeability and structure of the wood of sitka spruce. In : Proc. Roy. Soc. Lond. B175: 149-166.

Petty, J.A., Puritch. G.S. (1980) The effect of drying on the structure and permeability of the wood of Abies grandis. Wood Sci. Technol. 14:49-62.

Redman, A., Bailleres, H., Turner, I., Perré, P. (2012) Mass transfer properties (permeability and mass diffusivity) of four Australian hardwood species. BioResources 7(3):34103424.

Rice, R.W. (1996) Longitudinal gas permeability measurements from eastern white pine, red spruce, and balsam fir. Wood Fiber Sci., 28(3): 301-308.

Rogério, M., Oliveira, G., Deiner, J., Calil, C. (2010) Permeability Measurements of Brazilian Eucalyptus. Mat. Res. 13(3): 281-286.

Siau, J.F. (1984) Transport processes in wood. Springer Verlag, New-York.

Tanaka, T., Kawai, Y., Sadanari, M., Shida, S., \& Tsuchimoto, T. (2015). Air permeability of sugi (Cryptomeria japonica) wood in the three directions. Maderas. Ciencia y Tecnología, 17, 17-28.

Taghiyari, H. (2013) Effects of heat-treatment on permeability of untreated and nanosilverimpregnated native hardwoods. Maderas. Ciencia Y Tecnología, 15(ahead), 183-194.

Tarmian, A., Perré, P. (2009) Air permeability in longitudinal and radial direction of reaction wood as compared to normal wood: compression wood of Picea abies and tension wood of Fagus sylvatica. Holzforschung 63:352-356.

Usta, I., Hale, M. (2006) Comparison of the bordered pits of two species of spruce (Pinaceae) in a green and kiln-dried condition and their effects on fluid flow in the stem wood in relation to wood preservation. Forestry 79:467-475.

Wägner F., Schober G., Mörtel H. (1995) Measurement of the gas permeability of autoclaved aerated concrete in conjunction with its physical properties. Cement and Concrete Research 25:1621-1626.

Wang, J., Dai, C., Liu, Y. (1991) Wood permeability. J. Northeast For. Univ. Vol. 2, No. 1.

Wheeler, E.A., Baas, P., Gasson, P.E. (1989) IAWA list of microscopic features for hardwood identification. IAWA Bulletin 10:219-332.

Wang, J.Z., DeGroot R. (1996) Treatability and durability of heartwood. National Conference on Wood Transportation Structures, U.S. Department of Agriculture, Forest Service, Forest Products Laboratory, Madison, WI, pp. 252-260. 
Wu, Y.S., Preuss, K., Persoff, P. (1998) Gas flow in porous media with Klinkenberg effects. Transp. Porous Media 32:117-137. 


\section{APPENDIX}

\section{Model used to analyze experiment performed under non-isothermal regime}

Further developments are needed when the temperature of the two tanks is not constant. From the definition of internal energy $U$ and the value of heat capacity at constant volume for an ideal gas $\left(C_{v}=n R /(\gamma-1)\right)$, the entropy variation $d S$ of an ideal gas can be expressed as a function of temperature and volume variations $(d T, d V)$ :

$$
d S=\frac{n R}{\gamma-1} \frac{d T}{T}+n R \frac{d V}{V}
$$

In Eq. (A1), the volume variation $d V$ is simply determined based on Darcy's law, Eq. (9), with the actual pressure gap. Additionally, the entropy variation is due to the heat flux between the reservoir walls and the gas. This heat flux is obtained by the internal heat transfer coefficient $h_{\text {int }}$ :

$$
d S=\frac{\delta Q}{T}=\frac{h_{\text {int }} A_{\text {tank }}\left(T_{\text {wall }}-T_{g}\right) d t}{T}
$$

Keeping in mind that the tank wall exchanges on both faces, the evolution of the wall temperature reads as

$$
m_{\text {wall }} c_{p, w a l l} d T_{\text {wall }}=A_{\text {tank }}\left[h_{\text {int }}\left(T_{g}-T_{\text {wall }}\right)+h_{\text {ext }}\left(T_{\text {ext }}-T_{\text {wall }}\right)\right] d t
$$

Eqs. (A1 to A3), together with Darcy's law, allow the temperature and volume increments over any small time step $d t$ to be obtained. From these increments, the pressure variations $d P_{1}$ and $d P_{2}$ are simply computed based on the derivative of the ideal gases law:

$$
\frac{d P}{P}+\frac{d V}{V}=\frac{d T}{T}
$$


Eqs. (9) and (A1-14) were solved numerically to compute the evolution of pressure and temperature in tanks 1 and 2:

$\checkmark$ Set initial values

$\checkmark$ Loop from $t=0$ to $\tau$

- Compute $d V_{1}$ and $d V_{2}$ using Darcy's law (9) with current values of $P_{1}$ and $P_{2}$

- Compute $n_{1}$ and $n_{2}$ using $V_{1}$ and $V_{2}$ with current values of $T$ and $P$

- Compute $d S_{1}$ and $d S_{2}$ using the heat exchanges (A2)

- Substitute the previous values in (A1) to compute $d T_{1}$ and $d T_{2}$

- Compute $d P_{1}$ and $d P_{2}$ using (A4)

- Update the wall temperature using (A3)

- Actualize the values $P_{1}, P_{2}, T_{1}, T_{2}$, for the mole numbers at time $t$

- Update $T_{2}$ as mixture of $n_{2}$ at $T_{2}$ and $d n$ at $T_{1}$ entered in $V_{2}$ during $d t$

- $t=t+d t$

- Save data

$\checkmark$ End of loop

Remark: This formulation applies to a closed system (mole number $n$ constant). Therefore, at each time $t$, the mole number is computed with volumes $V_{1}$ and $V_{2}$ and the current values of pressure and temperature. During the time increment $d t$, the flux through the sample simply changes the volume of the system. A Joule-Thomson expansion occurs in the porous media, so the gas entering volume 2 is supposed to be at temperature $T_{1}$ (assumption of ideal gas).

The solution can easily be modified to simulate an adiabatic $(d S=0)$ or an isothermic configuration $(d T=0$, hence $d S=n R d V / V)$.

Simulations in real conditions require the heat exchange coefficients $\left(h_{\text {int }}\right.$ and $\left.h_{\text {ext }}\right)$ to be determined. Due to the thermal inertia of the tank walls, the external heat transfer coefficient $h_{e x t}$ has little effect on the device behaviour and was fixed at $12 W \cdot K^{-1} \cdot m^{-2}$. In contrast, the internal heat transfer coefficient $h_{\text {int }}$, which is a key parameter, was determined 
by inverse analysis. A simple experiment was performed for this purpose, in which the pressure evolution of both chambers was recorded in the absence of flux after a thermal perturbation. The latter was obtained by suddenly opening the by-path valve $\left(\mathrm{V}_{5}\right)$ in the presence of two different pressure values in volumes 1 and 2, which increased or decreased the temperature in volume of low or high pressure, respectively. A heat transfer coefficient of $4.3 W \cdot K^{-1} \cdot m^{-2}$ was found for $h_{i n t}$ (Figure A1).

Figure A2 depicts a series of simulations performed at atmospheric pressure with the large tank volumes and the sample support $\mathrm{S}_{2}$, designed for highly permeable samples. As expected, the adiabatic situation is always faster than the isothermic configuration due to the absence of heat exchange and because the tank temperature decreases in volume 1 (expansion) and increases in volume 2 (compression). Both effects act towards a reduction of the pressure gap. In the case of a highly permeable sample $\left(K=10^{-11} \mathrm{~m}^{2}\right.$, Figure A2a), the real configuration behaves as the adiabatic configuration at very short times, which is consistent. Very soon, the curve leaves the adiabatic behaviour: the decrease of the pressure gap evolves more slowly, crosses the isothermal curve, and eventually exhibits a slower evolution than the two ideal configurations. This is due to the inertia of the tank walls, whose temperature returns very slowly to the external temperature after the initial perturbation. This slow evolution is transferred to the gas and tends to maintain a pressure gap. The assumption of isothermal regime is confirmed for low permeable samples $\left(\leq 10^{-13} \mathrm{~m}^{2}\right)$.

The regime depends strongly on the test configuration. Our simulations insinuate that the system is almost perfectly isothermal even for highly permeable samples, $K=10^{-11} \mathrm{~m}^{2}$, when the measurement is performed at low pressure, $\bar{P}=20 \mathrm{mbar}$. In contrast, it is almost adiabatic for a quite low permeability, $K=10^{-13} \mathrm{~m}^{2}$, but with sample support $\mathrm{S}_{1}$ at $\bar{P}=1000$ mbar 
Table 1 - A summary of representative experimental works focused on gaseous permeability of wood.

\begin{tabular}{|c|c|c|c|c|}
\hline Authors & Species & $\begin{array}{c}\text { Anat. } \\
\text { directions }\end{array}$ & $\begin{array}{c}\text { Pressure } \\
\text { range }\end{array}$ & Mass flow determination \\
\hline Rice 1996 & $\begin{array}{l}\text { Eastern white pine, Red } \\
\text { spruce, Balsam fir }\end{array}$ & L & 1 bar & Gas flowmeter \\
\hline $\begin{array}{l}\text { Rogério } \\
\text { et al. } 2010\end{array}$ & $\begin{array}{l}\text { Eucalyptus grandis and } \\
\text { citriodora }\end{array}$ & L & 1 bar & Gas flowmeter \\
\hline Taghiyari 2013 & $\begin{array}{l}\text { Beech, poplar, } \\
\text { Hornbeam }\end{array}$ & L & 1 bar & $\begin{array}{c}\text { Water position in a tube } \\
\text { determined by electronic } \\
\text { sensors. }\end{array}$ \\
\hline $\begin{array}{l}\text { Cai and } \\
\text { Oliveira } 2007\end{array}$ & Subalpine fir & $\mathrm{L}, \mathrm{R}, \mathrm{T}$ & 1 bar & Rotameter flowmeter \\
\hline Wang 1991 & $\begin{array}{l}\text { Pine, poplar, larch, } \\
\text { birch }\end{array}$ & $\mathrm{L}, \mathrm{R}, \mathrm{T}$ & $1 \mathrm{bar}$ & $\begin{array}{c}\text { Change of water level in a } \\
\text { tube }\end{array}$ \\
\hline $\begin{array}{l}\text { Tanaka et al. } \\
2015\end{array}$ & Sugi & $L, R, T$ & 1 bar & $\begin{array}{c}\text { Change of water level in a } \\
\text { tube }\end{array}$ \\
\hline $\begin{array}{l}\text { Lu and } \\
\text { Avramidis } 1999\end{array}$ & $\begin{array}{l}\text { Red oak, red alder, } \\
\text { pine, Douglas-fir }\end{array}$ & L & $\begin{array}{l}100-400 \\
\text { mbar }\end{array}$ & $\begin{array}{l}\text { Rotameter flowmeter and } \\
\text { water level in a tube }\end{array}$ \\
\hline Lihra et al. 2000 & Balsam fir & $\mathrm{L}, \mathrm{R}, \mathrm{T}$ & 1-4 bar & Flowmeter \\
\hline $\begin{array}{l}\text { Petty and } \\
\text { Preston } 1969\end{array}$ & Some SW species & $L, T$ & $\begin{array}{l}1 \text { to } 700 \\
\mathrm{mmHg}\end{array}$ & $\begin{array}{c}\text { Change of water level in a } \\
\text { tube }\end{array}$ \\
\hline
\end{tabular}


Table 2 - Examples of errors done if assuming ideal conditions ( $V=24 l, \phi=72 \mathrm{~mm}$, $\ell=10 \mathrm{~mm}$ ).

\begin{tabular}{|c|c|c|c|}
\hline \multirow[b]{2}{*}{ Regime } & \multicolumn{3}{|c|}{ Error (\%) for $K_{a p p}\left(m^{2}\right)$} \\
\hline & $10^{-11}$ & $10^{-12}$ & $10^{-13}$ \\
\hline Isothermal ( $\bar{P} 20$ mbar $)$ & $2 \%$ & $0.21 \%$ & $0.01 \%$ \\
\hline Isothermal ( $\bar{P} 1,000 \mathrm{mbar})$ & $27 \%$ & $26 \%$ & $22 \%$ \\
\hline Adiabatic ( $\bar{P} 20 \mathrm{mbar})$ & $45 \%$ & $41 \%$ & $40 \%$ \\
\hline Adiabatic ( $\bar{P} 1,000$ mbar $)$ & $3 \%$ & $4 \%$ & $10 \%$ \\
\hline
\end{tabular}


Table 3 - The whole set of experimental data

\begin{tabular}{|c|c|c|c|c|}
\hline Material & $\underset{\text { le }}{\text { Samp }}$ & $K_{\infty}\left(m^{2}\right)$ & $b(P a)$ & $r(\mu m)^{1)}$ \\
\hline & T1 & $2.8610^{-18}$ & $1.0810^{05}$ & 0.246 \\
\hline Norway & Т 2 & $2.6710^{-18}$ & $1.1410^{05}$ & 0.233 \\
\hline \multirow[t]{4}{*}{ spruce } & L 1 & $2.2510^{-14}$ & $4.9810^{04}$ & 0.535 \\
\hline & L 2 & $2.6510^{-14}$ & $4.6810^{04}$ & 0.568 \\
\hline & T 1 & $2.2910^{-16}$ & $5.7510^{0.3}$ & 4.63 \\
\hline & $\mathrm{T} 2$ & $2.6110^{-16}$ & $3.9810^{03}$ & 6.68 \\
\hline \multirow{5}{*}{$\begin{array}{l}\text { European } \\
\text { beech }\end{array}$} & $\bar{R} \overline{1}$ & $9 . \overline{7} 8 \overline{10}=1 \Gamma$ & $\overline{1.53} \overline{1} 0^{-44}$ & $\overline{1.7 \overline{3}^{--}}$ \\
\hline & R 2 & $2.9010^{-1 /}$ & $9.7910^{04}$ & 0.272 \\
\hline & R 3 & $1.1010^{-16}$ & $2.5410^{04}$ & 1.05 \\
\hline & L 1 & $5.8910^{-12}$ & $3.5010^{03}$ & 7.61 \\
\hline & $\perp 2$ & $5.8910^{-12}$ & $3.9910^{03}$ & 6.67 \\
\hline Fibreboard & 1 & $6 . \overline{7} 10^{-1 \Gamma}$ & $\overline{2} . \overline{6} \overline{1} \overline{10}$ & $9.8 \overline{7}^{--}$ \\
\hline (LDF) & 2 & $6.5810^{-11}$ & $1.6710^{03}$ & 15.69 \\
\hline Light concrete & 1 & $2 . \overline{6} 410^{-15}$ & $\overline{1} .0 \overline{2} \overline{10} 0^{-04}$ & $\overline{2} . \overline{1}-$ \\
\hline$(A A C)$ & 2 & $3.3010^{-13}$ & $3.6510^{03}$ & 7.30 \\
\hline MDF & 1 & & & 7.02 \\
\hline & 2 & $3.3510^{-13}$ & $3.6410^{03}$ & 7.31 \\
\hline
\end{tabular}

1) The radius values were computed with $c=1$ 


\section{LIST OF FIGURES}

Figure 1 - Sampling and sample geometry for the different materials tested: wood in longitudinal (L), radial (R), and tangential (T) directions, autoclaved aerated concrete (AAC), low density fibreboard,.and medium density fibreboard (MDF).

Figure 2 - Experimental device: general view and zoom in the sample support for longitudinal wood samples.

Figure 3 - Examples of pressure relaxation recorded for a set of contrasted samples. For wide range measurements the parameters have to be selected carefully: experiment time, sample geometry (using either support $\mathrm{S}_{1}$ or $\mathrm{S}_{2}$ ), sample thickness, and tank volumes.

Figure 4 - Pressure relaxations of P1 (pressure in the upstream chamber) and P2 (pressure in the downstream chamber) as a function of time in the two gas chambers for a sample of Norway spruce in the tangential direction (a) and evolution of the logarithm of pressure difference, entire set of data (b), and zoom over the very last instants with very small pressure gap (c).

Figure 5 - The comprehensive set of experimental measurements. For each sample, the apparent permeability $K_{a p p}$ is plotted versus the inverse of mean pressure of Norway spruce and European beech species in transverse directions under an isothermal regime.

Figure 6 - Apparent permeability plotted versus the inverse of average pressure. Results for permeable samples analysed by inverse method with the numerical model.

Figure 7 - The slip factor $b$ plotted versus permeability for the whole set of samples tested in the present work. The effective pore radius is computed using equation (16) with $c=1$.

Figure A1 - Identification of the internal heat transfer coefficient using the evolution of the device without any flux after a thermal perturbation.

Figure A2 - Experiment simulation: evolution of temperatures and logarithm of pressure

difference for $K_{a p p}=10^{-11}, 10^{-12}$ and $10^{-13} \mathrm{~m}^{2}$ (subplots a1, a2, b1, b2 and c1, c2 respectively). $V=24 l, \phi=18 \mathrm{~mm}, \ell=30 \mathrm{~mm}$, and $\bar{P}=1000 \mathrm{mbar}$. 
Figure 1
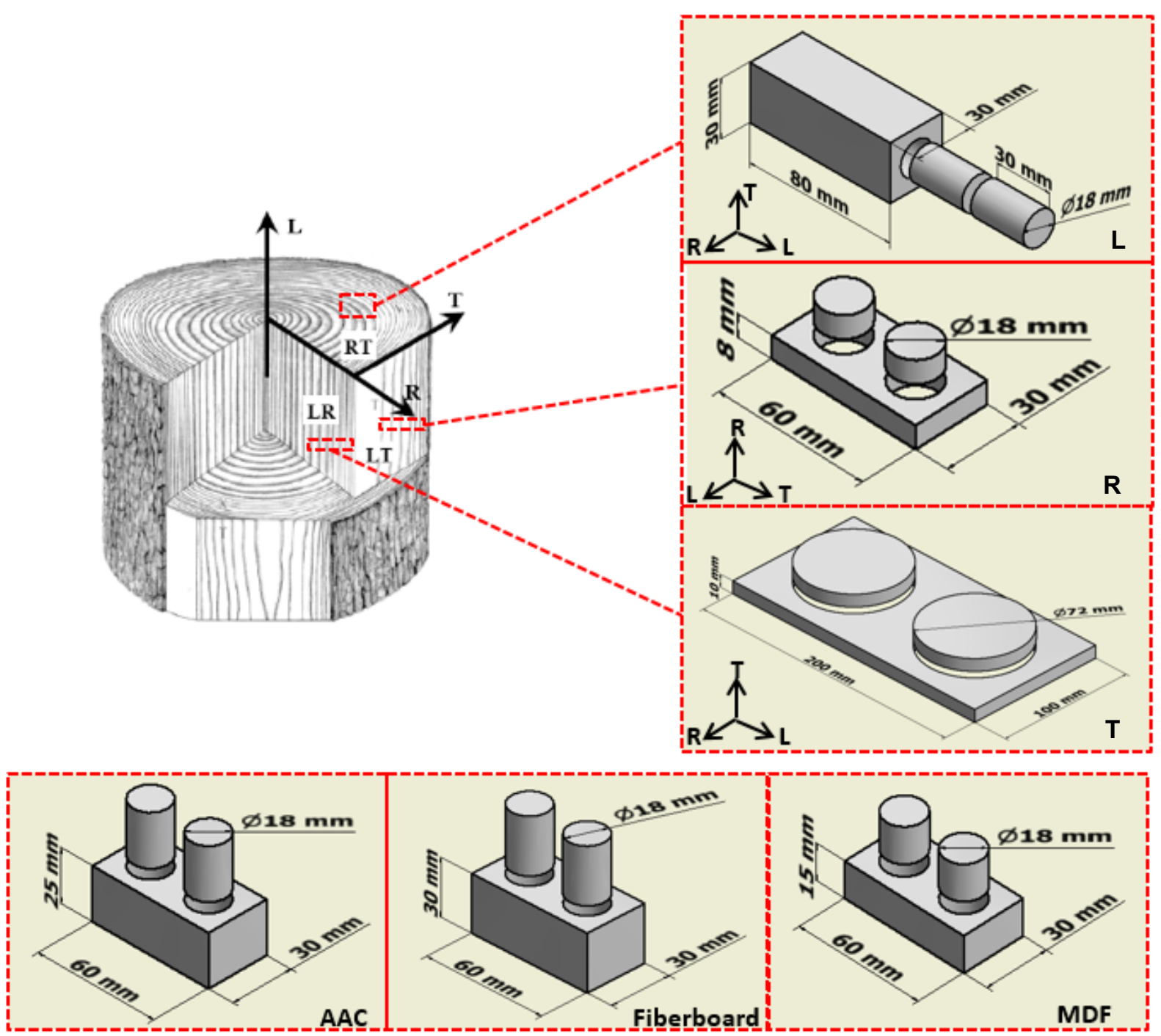
Figure 2

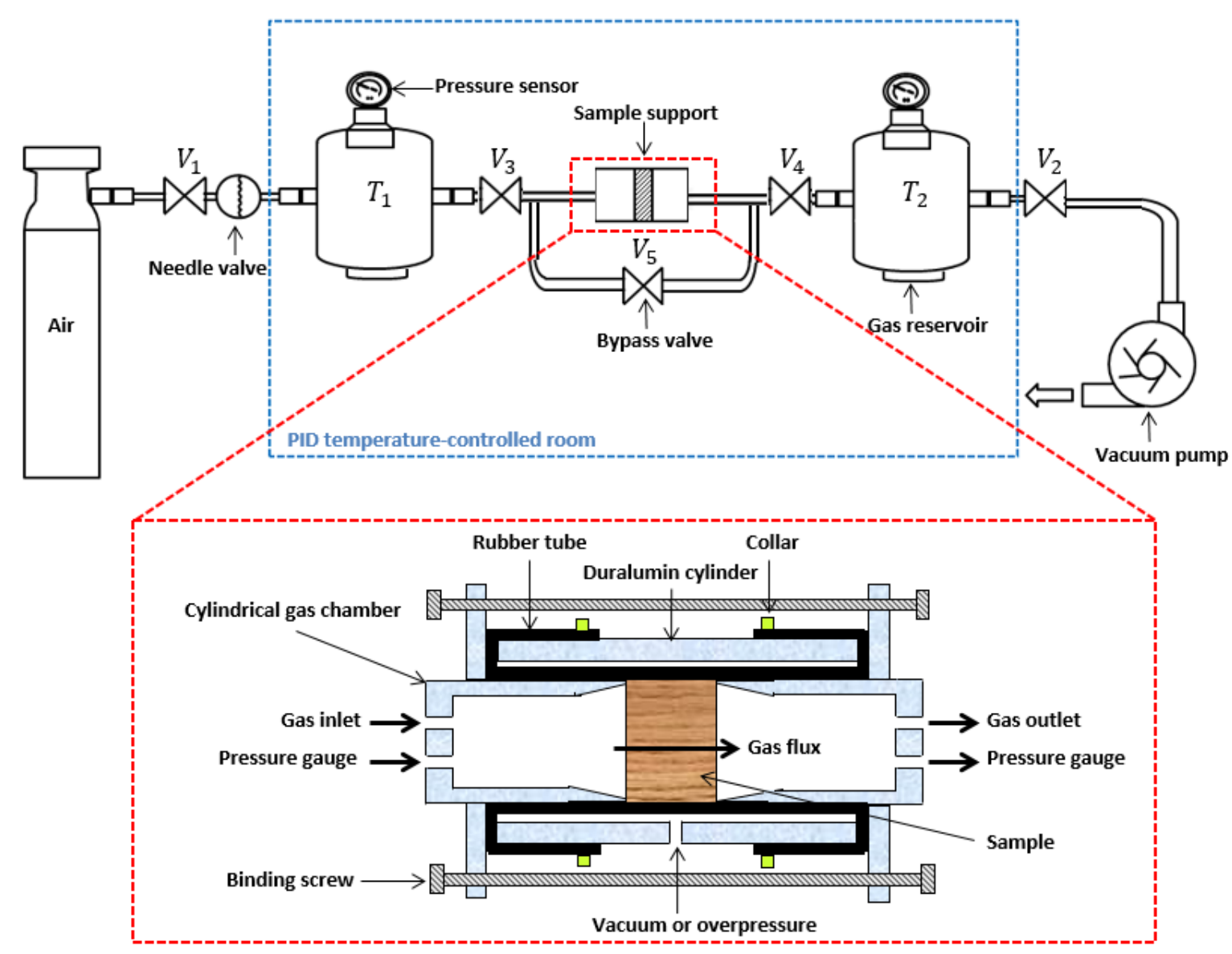


Figure 3
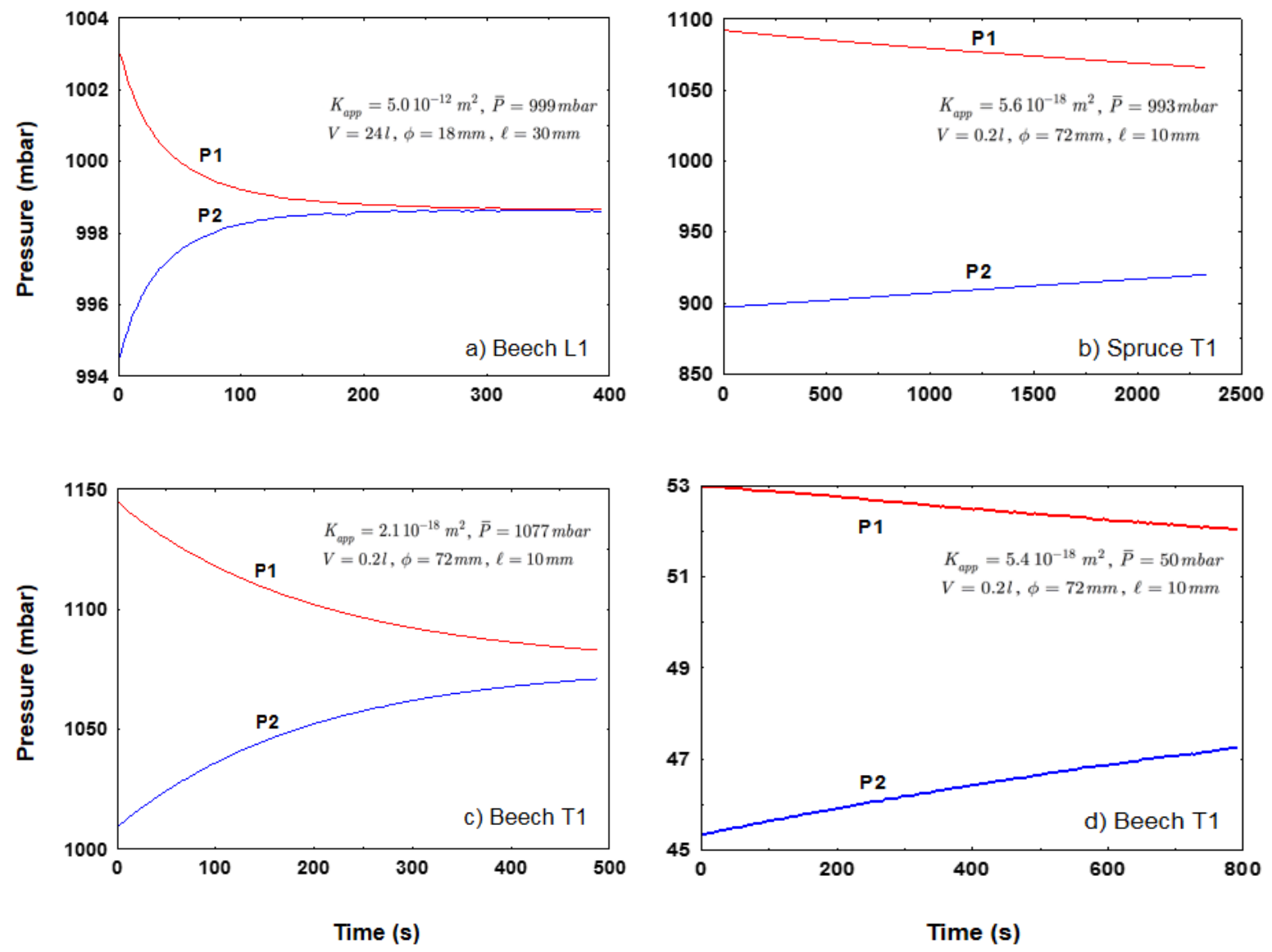
Figure 4
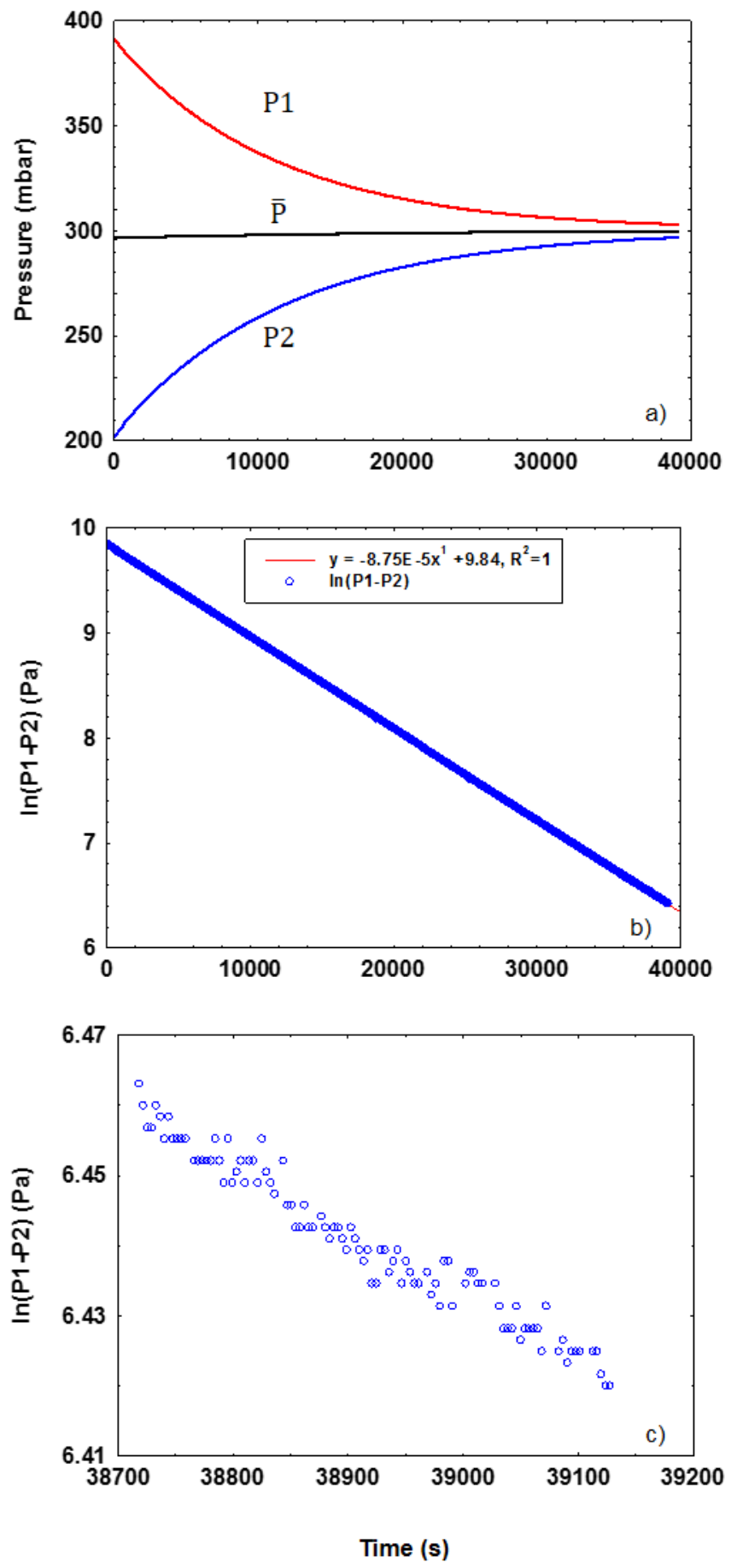
Figure 5
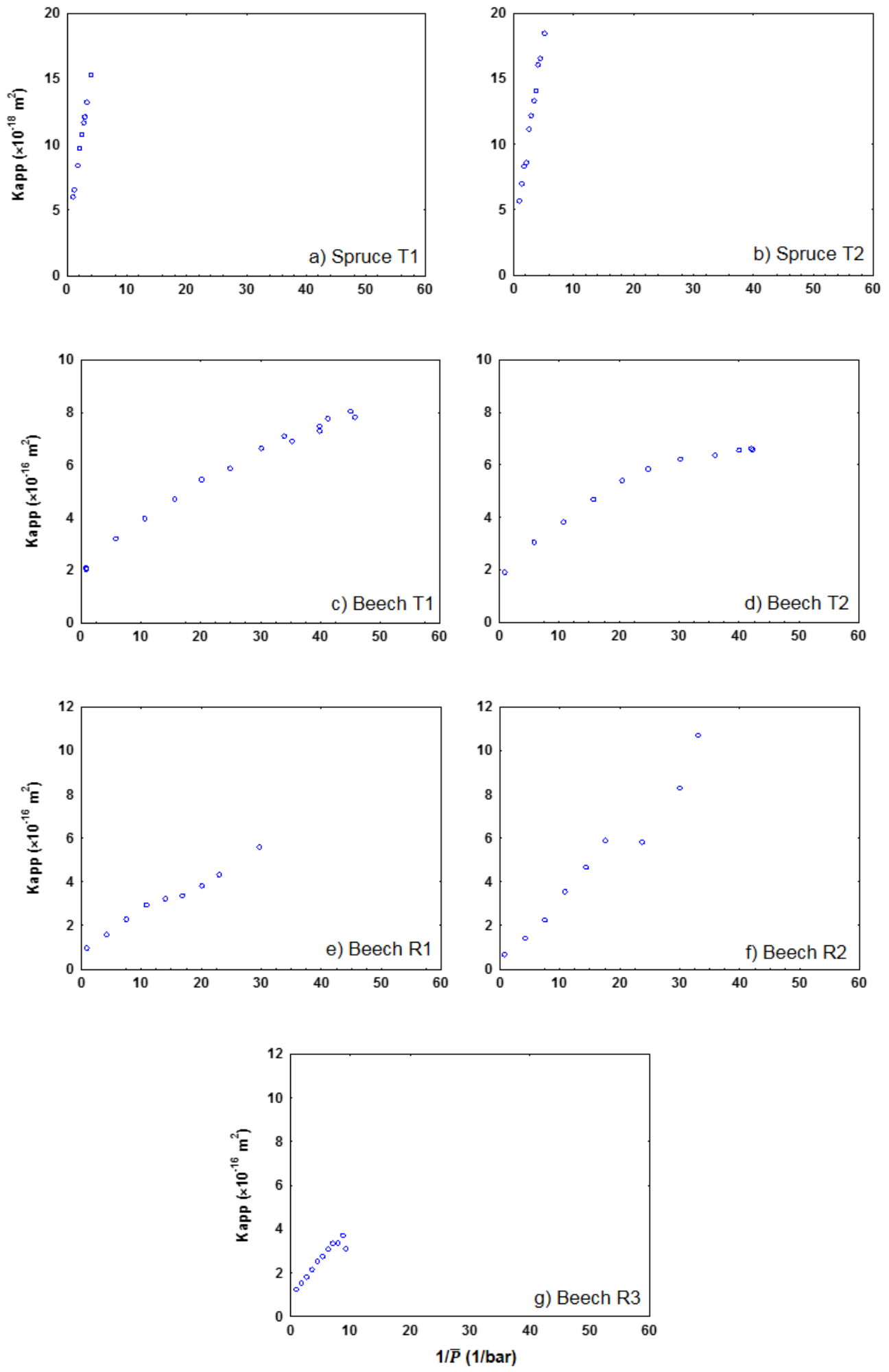
Figure 6
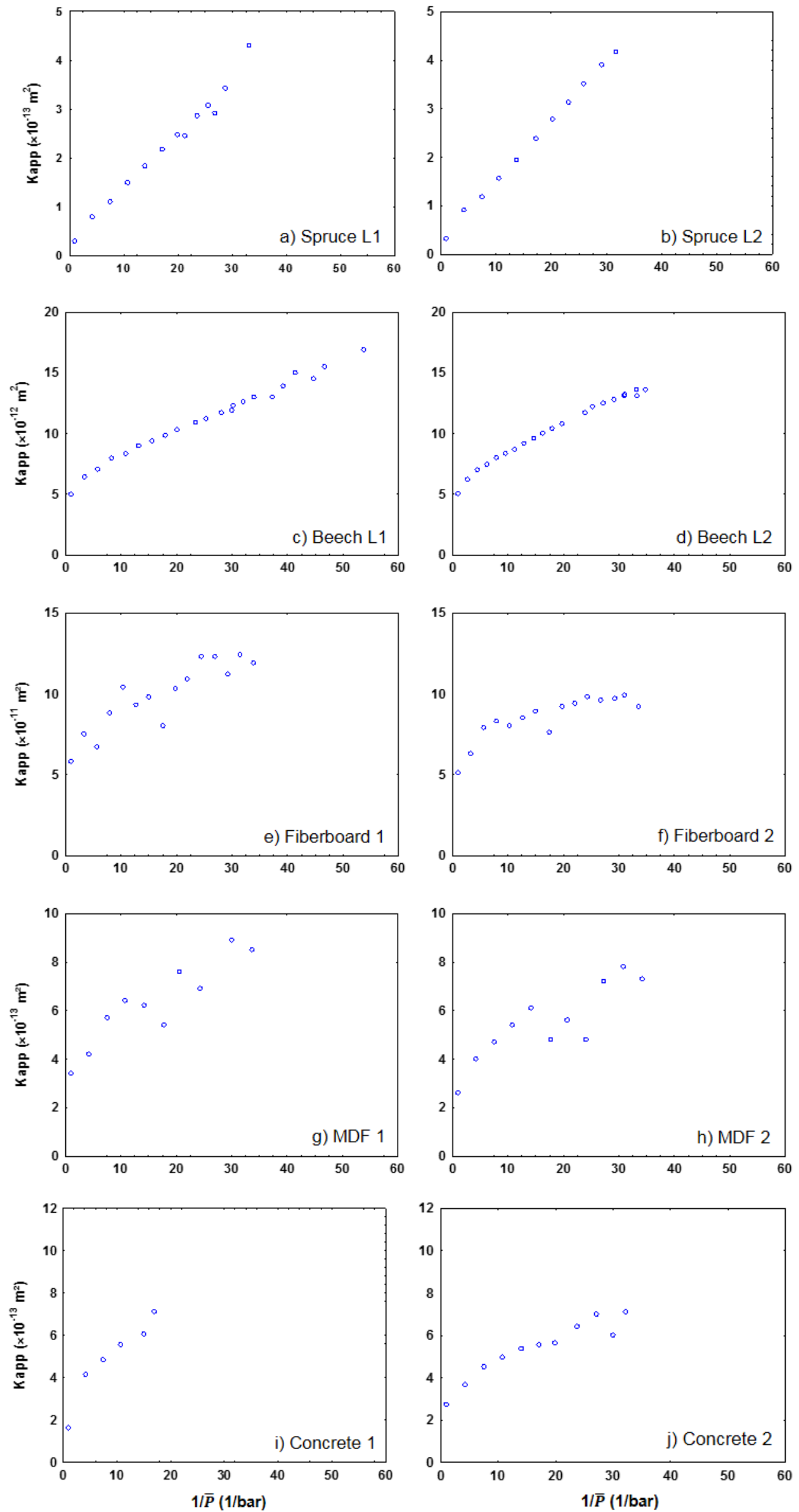
Figure 7

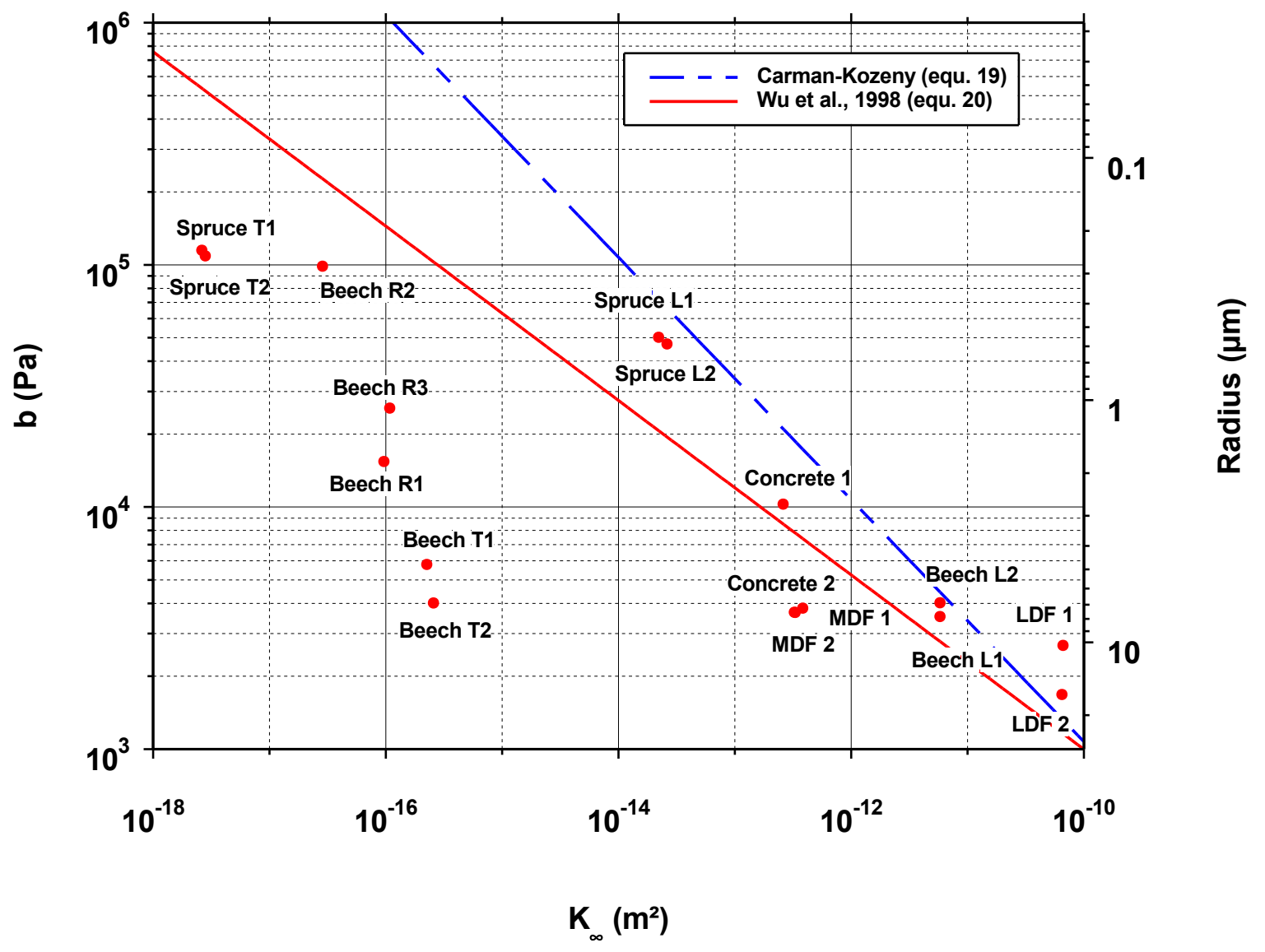


Figure A1

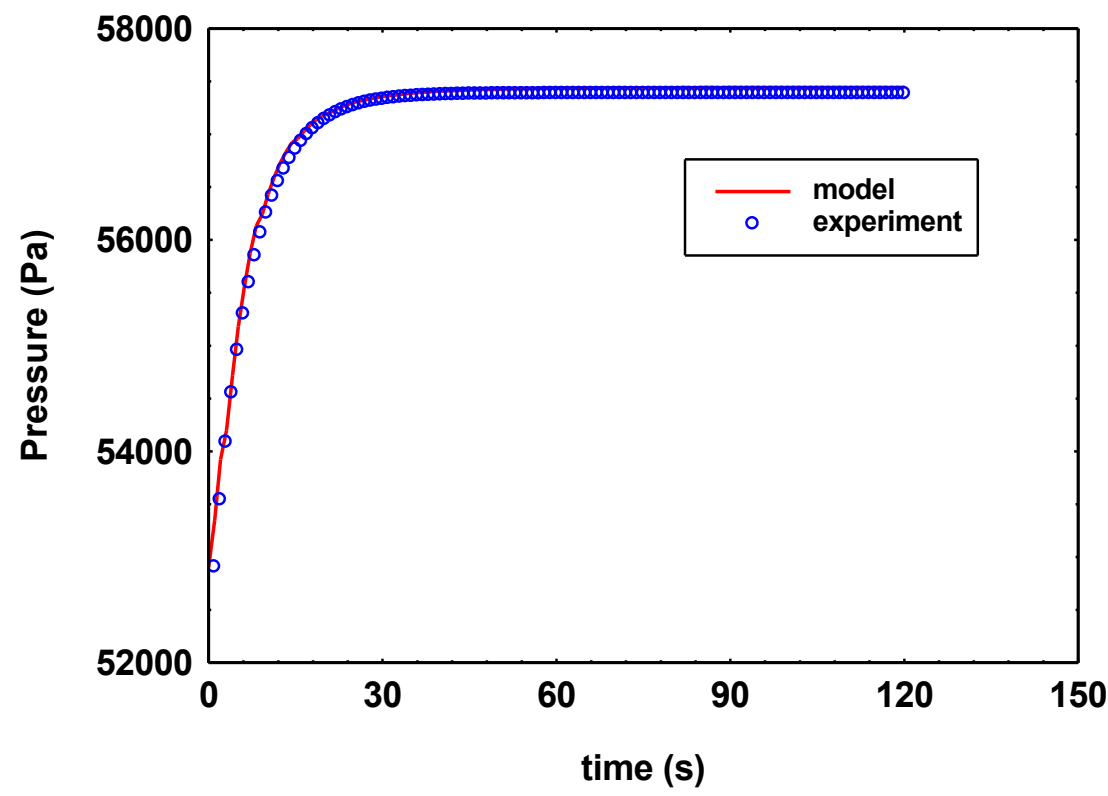


Figure A2
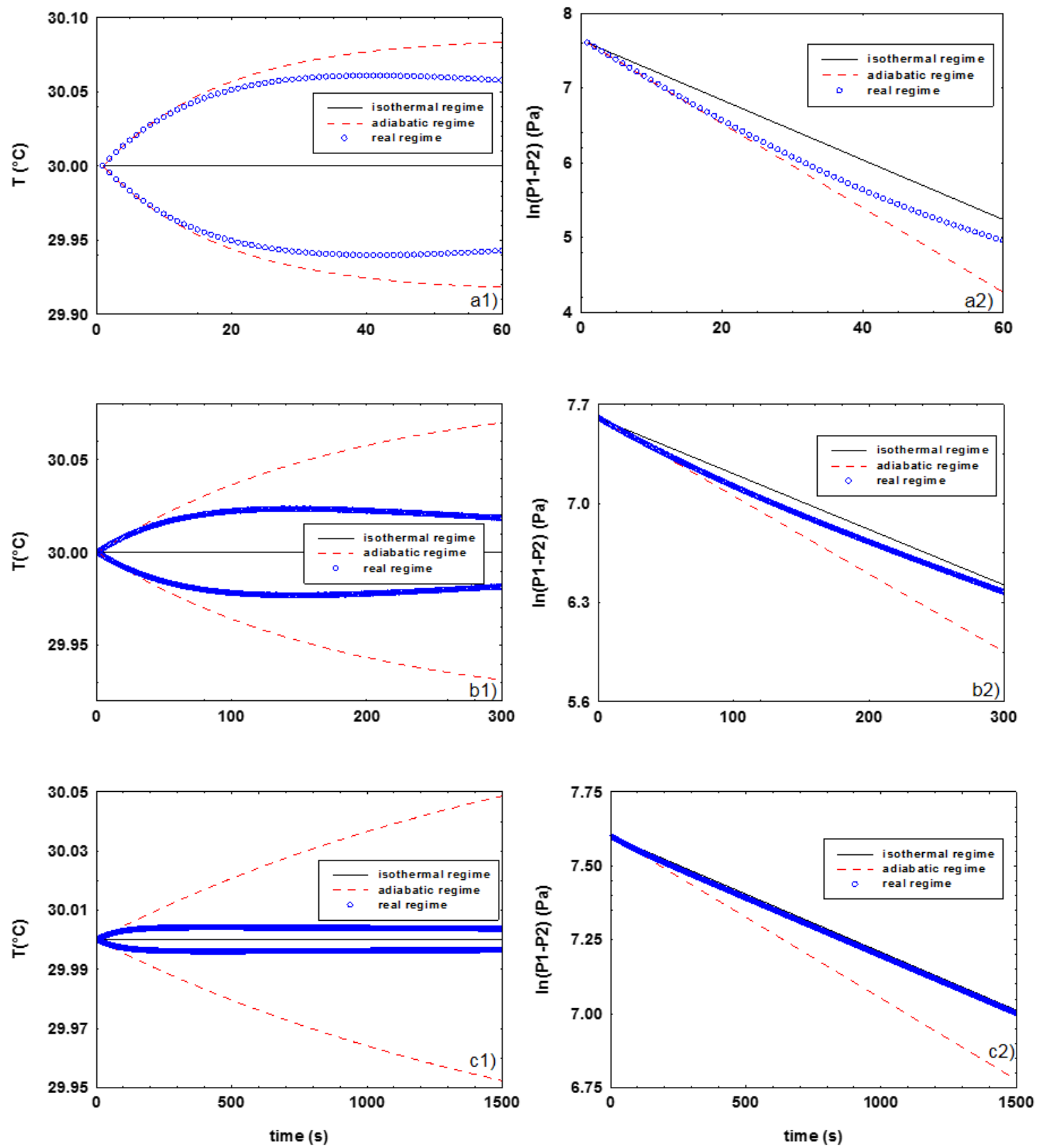